\title{
Alternating copolymerization of cyclic germylenes with $N$-phenyl-p-quinoneimine via oxidation-reduction process
}

\author{
Hiroshi Takano ${ }^{1}$, Masafumi Hiraishi ${ }^{1}$, Shigeru Yaguchi $^{1}$, Satoru Iwata ${ }^{1}$, Shin-ichiro Shoda ${ }^{1}$ \\ and Shiro Kobayashi ${ }^{1,2}$
}

Polymer Journal (2016) 48, 969-972; doi:10.1038/pj.2016.59; published online 15 June 2016

\section{INTRODUCTION}

Divalent germanium species (germylenes) continue to attract a great deal of interest as a heavy carbene analogue in the organometallic chemistry $^{1-4}$ and polymerization chemistry fields. ${ }^{5,6}$ As part of a series reporting our investigations on polymer synthesis via low valent 14 th group elements, we reported new polymerization reactions using a germylene as a monomer (oxidation-reduction copolymerization): copolymerization of germylenes with $p$-benzoquinones, ${ }^{5-9} \alpha, \beta$-unsaturated ketones, ${ }^{10-12}$ thiethane, ${ }^{13}$ and thiiranes. ${ }^{14}$ The germylene and acetylene monomer copolymerize, at room temperature, in the presence of a Rh catalyst. ${ }^{15}$ Similar copolymerization reactions were observed not only with germylenes but also with stannylenes. ${ }^{16,17}$ There are recent reports of the synthesis of Ge-containing polymers of the germylene-ethynylene type, and the optical properties of the copolymer were measured. ${ }^{18}$

As a result of the study of the copolymerization between germylenes and $p$-benzoquinones, we proposed the new biradical copolymerization mechanism based on detailed NMR, electron spin resonance (ESR), and UV-VIS spectroscopic investigations. ${ }^{8}$ We also found that the periodicity of the resulting copolymer strongly depends on the structure of germylenes; the use of an acyclic germylene gave 1:1 alternating copolymers, ${ }^{7,8}$ whereas five- and six-membered cyclic germylenes produced 2:1 periodic copolymers. ${ }^{9}$

Very recently, we reported a new copolymerization between an acyclic germylene and $N$-phenyl-p-quinoneimine, producing a 1:1 alternating copolymer of high molecular weight, in high yields. ${ }^{19}$ Here, we report a new 1:1 oxidation-reduction alternating copolymerization of cyclic germylenes (1a-1c) with $N$-phenyl-p-quinoneimine (2), which is an extension of our previous study. ${ }^{19} \mathbf{1 a}$ is a five-membered, $\mathbf{1 b}$ is a six-membered, and $\mathbf{1 c}$ is a seven-membered cyclic germylene, and they all have a $\mathrm{Me}_{3} \mathrm{Si}-\mathrm{N}$ group. 1 served as a reductant monomer whereas $\mathbf{2}$ as an oxidant monomer to give copolymers (3) (Scheme 1). In contrast to the previous observation, where the use of cyclic germylenes lead to the formation of $2: 1$ periodic copolymers, ${ }^{9}$ the present copolymerization using monomer 2 produces all 1:1 alternating copolymers (3a-3c).

\section{EXPERIMENTAL PROCEDURE}

Materials

Preparation of $\mathbf{1 a}$ and $\mathbf{1 b}$ was previously reported. ${ }^{9} \mathbf{1 c}$ was prepared under argon by the reaction of $\mathrm{GeCl}_{2} 1,4$-dioxane complex with the corresponding lithium amide as previously described, ${ }^{8}$ boiling point; $76{ }^{\circ} \mathrm{C} / 0.10 \mathrm{mmHg},{ }^{1} \mathrm{H}$ NMR $\left(\mathrm{C}_{6} \mathrm{D}_{6}\right) \delta 0.23\left(\mathrm{~s}, \mathrm{SiCH}_{3}, 18 \mathrm{H}\right), 1.58$ (s, $\left.\mathrm{NCH}_{2} \mathrm{CH}_{2}, 4 \mathrm{H}\right) .3 .36\left(\mathrm{~s}, \mathrm{NCH}_{2}, 4 \mathrm{H}\right) ;{ }^{13} \mathrm{C} \operatorname{NMR}\left(\mathrm{C}_{6} \mathrm{D}_{6}\right) \delta 1.2$ $\left(\mathrm{SiCH}_{3}\right), 30.6\left(\mathrm{NCH}_{2} \mathrm{CH}_{2}\right), 46.1\left(\mathrm{NCH}_{2}\right), 2$ was obtained before. ${ }^{19}$ Tetrahydrofuran (THF) was distilled before use. Other solvents were commercial reagents and used as obtained.

\section{Copolymerization}

Typically, the copolymerization of $\mathbf{1 c}$ with $\mathbf{2}$ was carried out as follows: To a THF solution of 1c $(0.13 \mathrm{~g}, 0.43 \mathrm{mmol}$ in $2.2 \mathrm{~mL}$ of THF) was added a $2.1 \mathrm{~mL}$ solution of THF containing $2(0.079 \mathrm{~g}, 0.43 \mathrm{mmol})$ at $-78^{\circ} \mathrm{C}$, with stirring, under argon. After stirring at $-78^{\circ} \mathrm{C}$ for $30 \mathrm{~min}$, the reaction mixture was poured into $50 \mathrm{~mL}$ of acetonitrile, with stirring. A white precipitate was obtained, collected by filtration, and dried in vacuo to yield $0.11 \mathrm{~g}(51 \%)$ of copolymer $3 \mathrm{c}:{ }^{1} \mathrm{H}$ NMR $\left(\mathrm{CDCl}_{3}\right) \delta-0.08\left(\mathrm{~s}, \mathrm{SiCH}_{3}, 18 \mathrm{H}\right), 1.59\left(\mathrm{~s}, \mathrm{NCH}_{2} \mathrm{CH}_{2}, 4 \mathrm{H}\right), 3.02$ (s, $\left.\mathrm{NCH}_{2}, 4 \mathrm{H}\right), 6.60-7.10(\mathrm{~m}, \mathrm{Ar}-\mathrm{H}, 9 \mathrm{H}) ;{ }^{13} \mathrm{C} \mathrm{NMR}\left(\mathrm{CDCl}_{3}\right) \delta-0.9$ $\left(\mathrm{SiCH}_{3}\right), 32.5\left(\mathrm{NCH}_{2} \mathrm{CH}_{2}\right), 45.4\left(\mathrm{NCH}_{2}\right)$ 120.6, 123.3, 128.4, 128.8 ( $\mathrm{CH}$ of $\mathrm{Ar}), 140.4$ (C-NPh), $150.4(C-\mathrm{N}), 153.7$ (C-O).

Copolymerizations of $\mathbf{1 a}$ and $\mathbf{1 b}$ with $\mathbf{2}$ were similarly performed and ${ }^{1} \mathrm{H}$ and ${ }^{13} \mathrm{C}$ NMR data for the copolymers are as follows: $3 \mathrm{a}:{ }^{1} \mathrm{H}$ NMR $\left(\mathrm{CDCl}_{3}\right) \delta-0.06$ (br. s, $\left.\mathrm{SiMe}_{3}, 18 \mathrm{H}\right), 6.38-7.06$ (br. m, Ar- $\mathrm{H}$, $13 \mathrm{H}) ;{ }^{13} \mathrm{C} \mathrm{NMR}\left(\mathrm{CDCl}_{3}\right) \delta-0.1\left(\mathrm{SiCH}_{3}\right) 114.4,118.5,119.3,121.8$, 123.5, 128.7 (CH of Ar), 138.3 (C-N-o-phenylene), 140.1 (C-N-phenyl), 149.1 ( $C$-N-p-phenylene), 152.8 (C-O-p-phenylene). 3b: ${ }^{1} \mathrm{H}$ NMR $\left(\mathrm{CDCl}_{3}\right) \delta-0.09$ (br. s, $\left.\mathrm{SiCH}_{3}, 18 \mathrm{H}\right), 1.64\left(\mathrm{~s}, \mathrm{NCH}_{2} \mathrm{CH}_{2}\right.$, 2H). 3.15 (s, $\left.\mathrm{NCH}_{2}, 4 \mathrm{H}\right), 6.65-7.18(\mathrm{~m}, \mathrm{Ar}-\mathrm{H}, 9 \mathrm{H}) ;{ }^{13} \mathrm{C} \mathrm{NMR}\left(\mathrm{CDCl}_{3}\right)$

${ }^{1}$ Department of Materials Chemistry, Graduate School of Engineering, Tohoku University, Aoba-ku, Sendai, Japan and ${ }^{2}$ Center for Fiber \& Textile Science, Kyoto Institute of Technology, Matsugasaki, Kyoto, Japan

Correspondence: Professor S Kobayashi, Center for Fiber \& Textile Science, Kyoto Institute of Technology, Matsugasaki, Sakyo-ku, Kyoto 606-8585, Japan.

E-mail: kobayash@kit.ac.jp

Received 1 March 2016; revised 18 April 2016; accepted 19 April 2016; published online 15 June 2016 


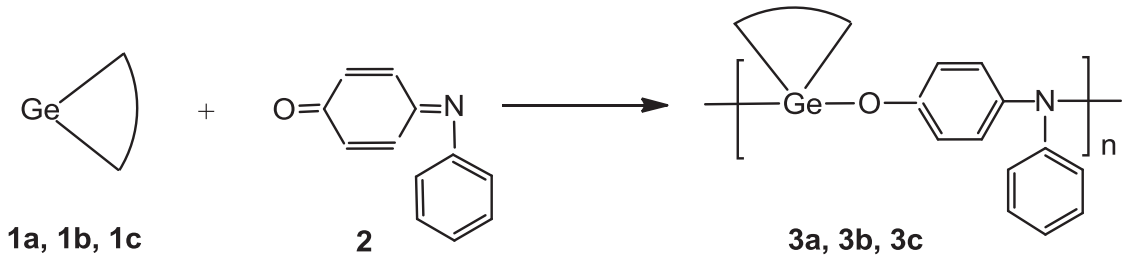

$1 a, 1 b, 1 c$<smiles>C1CC1</smiles><smiles>CN(C)c1ccccc1N(C)C</smiles>

a<smiles>CN(C)CCCN(C)C</smiles>

b<smiles>CS(C)(C)N1CCCCN(S(C)(=O)=O)C1</smiles>

c

Scheme 1 Alternating copolymerization of cyclic germylene (1) with $N$-phenyl-p-quinoneimine (2) to produce an alternating copolymer (3).

Table 1 Alternating copolymerization of cyclic germylene (1) with $N$-phenyl-p-quinoneimine (2) under various reaction conditions

Copolymerization ${ }^{\mathrm{a}}$

Monomer feed molar ratio

\begin{tabular}{|c|c|c|c|c|c|c|c|}
\hline Code & Germylene & $1: 2$ & Time (min) & Yield $(\%)$ & $M_{w} \times 10^{-4 c}$ & $M_{w} / M_{n}^{c}$ & Structure \\
\hline 1 & $1 a$ & $1.0: 1.0$ & 30 & 57 & 3.31 & 2.59 & $3 a$ \\
\hline 2 & $1 \mathrm{a}$ & $1.0: 2.0$ & 30 & 70 & 5.69 & 2.43 & $3 a$ \\
\hline 3 & $1 b$ & $1.0: 1.0$ & 30 & 66 & 11.7 & 3.39 & $3 b$ \\
\hline 5 & $1 b$ & $2.0: 1.0$ & 60 & $\sim 100$ & 18.6 & 1.51 & $3 b$ \\
\hline 6 & $1 c$ & $1.0: 1.0$ & 30 & 51 & 17.2 & 1.4 & $3 c$ \\
\hline
\end{tabular}

aCopolymerization was carried out in THF at $-78^{\circ} \mathrm{C}$ under argon.

bIsolated yields, based on the $1.0: 1.0$ molar stoichiometry of the copolymer structure.

${ }^{\mathrm{c}}$ Determined by GPC.

$\delta-0.5\left(\mathrm{SiCH}_{3}\right), 31.6\left(\mathrm{NCH}_{2} \mathrm{CH}_{2}\right), 46.2\left(\mathrm{NCH}_{2}\right)$ 120.3, 120.4, 123.5, 128.3 ( $C \mathrm{H}$ of $\mathrm{Ar}), 140.6(C-\mathrm{NPh}), 150.7(C-\mathrm{N}), 153.6(C-\mathrm{O})$.

\section{Analytical methods}

${ }^{1} \mathrm{H}$ and ${ }^{13} \mathrm{C}$ NMR measurements were conducted on a Bruker AC-250 T spectrometer (Yokohama, Japan). Gel permeation chromatographic (GPC) analysis was carried out by using chloroform as eluent, employing polystyrene as standard.

\section{RESULTS AND DISCUSSION}

\section{Copolymerization reaction}

The copolymerization is shown by Scheme 1. Germylenes are so air-sensitive that the copolymerization was carried out under argon atmosphere. Germylene monomers (1a-1c) reacted very rapidly at $-78^{\circ} \mathrm{C}$ in $\mathrm{THF}$ with monomer 2 , giving rise to alternating copolymer (3) within $60 \mathrm{~min}$. The copolymerization results are given in Table 1.

Three cyclic germylenes (1a-1c) in combination with 2 gave alternating copolymers (3a-3c) with high molecular weight in all reactions. It is to be noted that cyclic germylene 1c (seven-membered) has been studied for the first time here in the oxidation-reduction copolymerizations. ${ }^{7-9,19}$ As a typical example (Code 6), the reaction of germylene $\mathbf{1 c}$ with 2 in a 1.0:1.0 molar ratio produced copolymer $3 \mathrm{c}$ in $51 \%$ yield, having a $M_{\mathrm{w}}$ value of $1.72 \times 10^{5}$. The ${ }^{1} \mathrm{H}$ NMR spectrum of $3 \mathrm{c}$ is shown in Figure 1. The peak assignments are given in the figure, and the detailed chemical shift data are found in the above experimental section. The peak integral ratio of $\mathrm{SiCH}_{3}$ and the total aromatic protons is $18: 9$, which definitely shows the $1: 1$ composition structure and confirms the alternating structure. Figure 2 shows the ${ }^{13} \mathrm{C}$ NMR spectrum of copolymer $3 \mathrm{c}$, supporting again the alternating structure. The peak assignments are given in the figure, with the detailed chemical shift data found in the experimental section. All these data clearly prove the 1:1 alternating structure of copolymer $\mathbf{3 c}$.

In a similar way, the copolymer structures of $\mathbf{3 a}$ and $\mathbf{3 b}$ were determined using ${ }^{1} \mathrm{H}$ and ${ }^{13} \mathrm{C}$ NMR spectroscopic methods, and the detailed signal assignment data are given in the experimental section. These data confirm the 1:1 alternating copolymer structure in all cases (Codes 1-5), as indicated in Table 1. With the different monomer ratios, Codes 1 and 2 for $\mathbf{1 a}$ and Codes 4 and 5 for $\mathbf{1 b}$, respectively, the copolymers still showed the 1:1 alternating structure, and the alternating structure regulation was well kept, regardless of the monomer ratio. All of the copolymers were white powdery materials that were stable under air for more than a few months. They were not readily degraded due to the moisture in air.

For the mechanism of the copolymerization, monomers 1 and 2 first form biradical 4 via a highly reactive oxidation-reduction process, which is considered a key intermediate in producing the $1: 1$ alternating copolymer (Scheme 2). Once the intermediate $\mathbf{4}$ is formed, the following steps, involving a biradical method (fully discussed by ESR spectroscopic studies in previous reports), results in the formation of the alternating copolymer. ${ }^{19}$ The formation of a biradical (4) having a germyl radical and a nitrogen radical from $\mathbf{1}$ and $\mathbf{2}$ seems to be much preferable to the formation of a biradical having germyl and oxygen radicals. This is due to the higher stability of the nitrogen radical, 


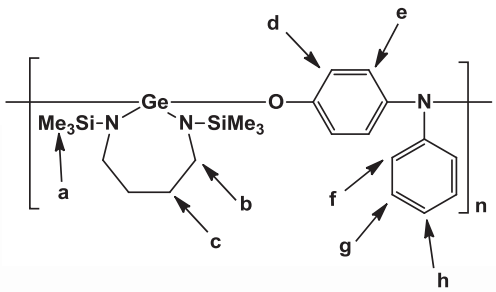

a

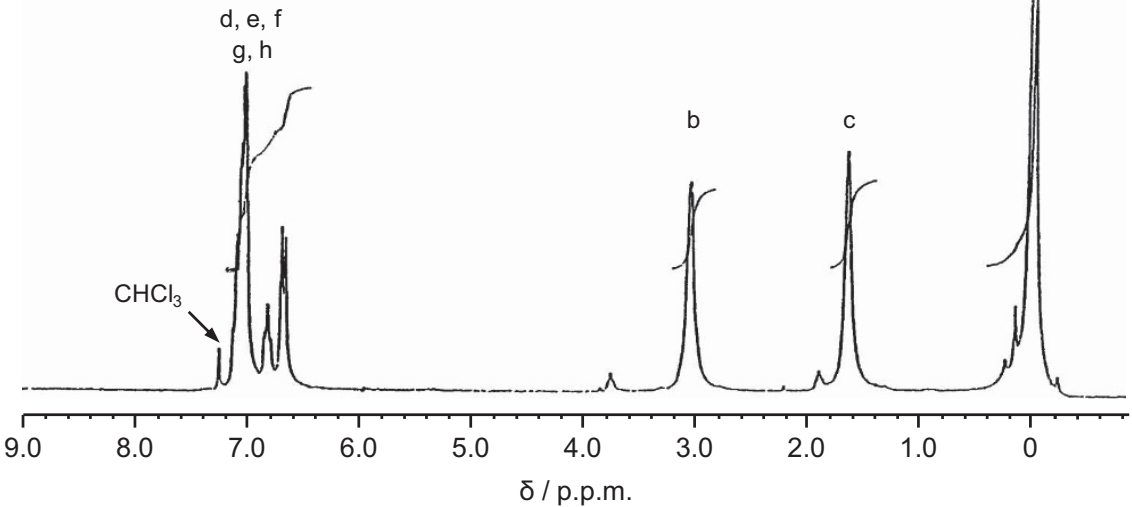

Figure $1{ }^{1} \mathrm{H}$ NMR spectrum of copolymer $3 \mathrm{c}\left(\mathrm{CDCl}_{3}\right)$.
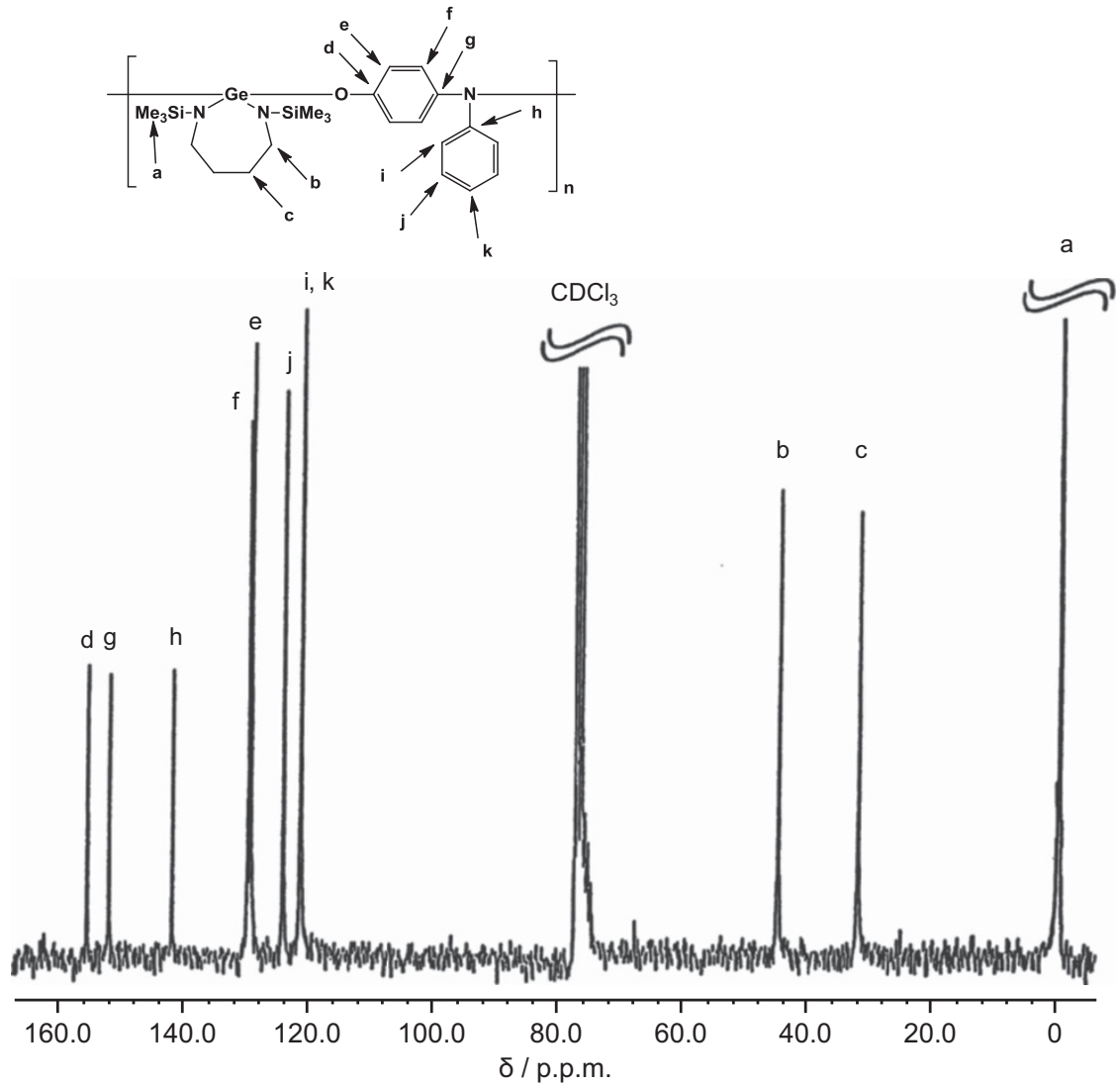

Figure $2{ }^{13} \mathrm{C}$ NMR spectrum of copolymer $3 \mathrm{c}\left(\mathrm{CDCl}_{3}\right)$. 


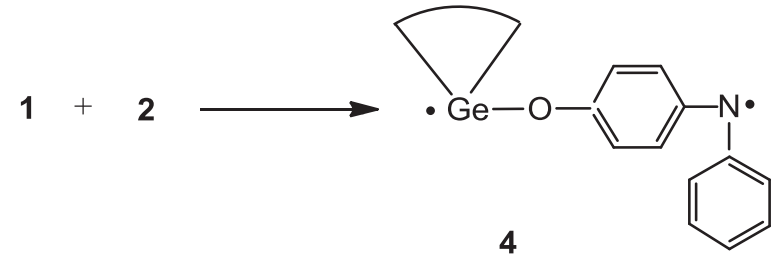

Scheme 2 Formation of a key-intermediate of biradical 4.

which is stabilized by the phenyl group, compared to the stability of the oxygen radical. In addition, the oxygen radical formation is less favored due to the steric repulsion between the $\mathrm{N}$-phenyl substituent and the trimethylsilylated substituents on the germylene. ${ }^{19}$

The copolymerization of cyclic germylenes $\mathbf{1}$ with a quinoneimine $\mathbf{2}$ gave 1:1 alternating copolymers 3 , regardless of the germylene structure. These results are quite different from those of the copolymerization of $\mathbf{1}$ with $p$-benzoquinones, which gave different type of copolymers depending upon the germylene structure, i.e., producing 1:1 alternating copolymers from acyclic germylenes ${ }^{7,8}$ and 2:1 periodic copolymers from cyclic germylenes such as $\mathbf{1 a}$ and $\mathbf{1} \mathbf{b} .^{9}$ The difference arises from the structural differences between the bond angles and the bond lengths of $\mathrm{C}-\mathrm{O}$ in the p-benzoquinones and $\mathrm{C}-\mathrm{NPh}$, which causes steric and reactivity differences in the intermediate radical species and leads to differential monomer reactivity; the nitrogen radical of $\mathbf{4}$ does not react with $\mathbf{1}$ but does react with the germyl radical. It is not possible, at this point, to completely exclude the Ge-Ge bond formation because such bond formation was previously noted. ${ }^{9}$ A more precise explanation requires further detailed studies.

\section{CONCLUSION}

Cyclic germylenes with five- (1a), six- (1b), and seven- (1c) membered rings, underwent the copolymerization with $N$-phenyl-p-quinoneimine (2) smoothly at $-78{ }^{\circ} \mathrm{C}$ to give copolymers ( $\mathbf{3 a}, \mathbf{3 b}$ and $3 \mathbf{c}$, respectively) having a tetravalent germanium unit and a $p$-aminophenol unit, alternatingly. These results are in striking contrast compared to those of the copolymerization of cyclic germylenes ( $\mathbf{1} \mathbf{a}$ and $\mathbf{1 b}$ ) with a $p$-benzoquinone, which gave 2:1 periodic copolymers.
1 Mizuhata, Y., Sasamori, T. \& Tokitoh, N. Stable heavier carbene analogues. Chem. Rev. 109, 3479-3511 (2009).

2 Asay, M., Jones, C. \& Driess, M. N-Heterocyclic carbene analogues with low-valent group 13 and group 14 elements: Syntheses, structures, and reactivities of a new generation of multitalented ligands. Chem. Rev. 111, 354-396 (2011).

3 Li, Y., Mondai, K. C., Stollberg, P., Zhu, H., Roesky, H. W., Herbst-Irmer, R., Stalke, D. \& Fliegt, $\mathrm{H}$. Unusual formation of a $\mathrm{N}$-heterocyclic germylene via homolytic cleavage of a C-C bond. Chem. Commun. 50, 3356-3358 (2014).

4 Iwata, S., Shoda, S. \& Kobayashi, S. Synthesis of a novel cyclic germanium enamine from germylene and 2-vinylpyridine and its stereoselective Aldol type reaction with aldehyde. Organometallics 14, 5533-5536 (1995).

5 Shoda, S., Uyama, H., Kobayashi, S. in Catalysis in precision polymerization. (ed. Kobayashi S.) Ch. 9, (John Wiley \& Sons Ltd, Chichester, England, 1997).

6 Kobayashi, S., Shoda, S., Iwata, S. in Desk references of functional polymers. (ed. Arshady R.)169-181 (American Chemical Society, Washington, DC, USA, 1997).

7 Kobayashi, S., Iwata, S., Abe, M. \& Shoda, S. New germanium-containing polymers via alternating copolymerization of a germylene with $p$-benzoquinone derivatives. J. Am. Chem. Soc. 112, 1625-1626 (1990).

8 Kobayashi, S., Iwata, S., Abe, M. \& Shoda, S. A novel redox process for the construction of germanium-containing polymers by utilizing germylenes and $p$-benzoquinone derivatives: First clear-cut evidence for a biradical propagation mechanism in polymerization chemistry. J. Am. Chem. Soc. 117, 2187-2200 (1995).

9 Kobayashi, S., Iwata, S. \& Hiraishi, M. Novel 2:1 periodic copolymers from cyclic germylenes and p-benzoquinone derivatives. J. Am. Chem. Soc. 116, 6047-6048 (1994).

10 Kobayashi, S., Iwata, S., Yajima, K., Yagi, K. \& Shoda, S. Poly(germanium enolate): A new class of polymer having a germanium enolate structure in the main chain. J. Am. Chem. Soc. 114, 4929-4931 (1992).

11 Kobayashi, S. \& Shoda, S. A novel metal-containing polymer: Poly(germanium enolate). Adv. Mater. 5, 57-59 (1993).

12 Shoda, S., Iwata, S., Yajima, K., Yagi, K., Ohnishi, Y. \& Kobayashi, S. Synthesis of germanium enolate polymers from germylene. Tetrahedron 53, 15281-15295 (1997).

13 Shoda, S., Iwata, S., Kim, H. J., Hiraishi, M. \& Kobayashi, S. Poly(germanium thiolate): a new class of organometallic polymers having a germanium-sulfur bond in the main chain. Macromol. Chem. Phys. 197, 2437-2445 (1996).

14 Kobayashi, S., Iwata, S., Kim, H. J. \& Shoda, S. Novel oxidation-reduction copolymerization of a germylene with ethylene or propylene sulfide producing a 1:1: $\alpha$ periodic copolymer. Macromolecules 29, 486-488 (1996).

15 Kobayashi, S. \& Cao, S. Copolymerization of a germylene with acetylene monomer by Rhodiun catalysis. Chem. Lett. 22, 25-28 (1993).

16 Kobayashi, S., Iwata, Abe, M., Yajima, K., Kim, H. J. \& Shoda, S. A germylene and stannylene as polymerization of comonomer and initiator. Macromol. Chem., Macromol. Symp. 54/55, 225-231 (1992).

17 Kobayashi, S., Iwata, S. \& Shoda, S. Oxidation-reduction alternating copolymerization of stannylenes with $p$-benzoquinone derivatives. Acta Polym. 46, 471-475 (1995).

18 Tanimoto, H., Nagao, T., Fujiwara, T., Kakuta, T., Tanaka, K., Chujo, Y. \& Kakiuchi, K. Fluorescence and phosphorescence study of germanium-acetylene polymers and germa [N]pericyclynes. Polym. Chem. 6, 7495-7499 (2015).

19 Iwata, S., Abe, M., Shoda, S. \& Kobayashi, S. Oxidation-reduction alternating copolymerization of germylene with $N$-phenyl-p-quinoneimine. Polym. J. 47, 31-36 (2015). 